Article

\title{
Enhanced Thermal Properties of Zirconia Nanoparticles and Chitosan-Based Intumescent Flame Retardant Coatings
}

\author{
Tentu Nageswara Rao@, Imad Hussain, Ji Eun Lee, Akshay Kumar and Bon Heun Koo* \\ School of Materials Science and Engineering, Changwon National University, Changwon, Gyeongnam 51140, \\ Korea \\ * Correspondence: bhkoo@changwon.ac.kr; Fax: +82-(55)-262-6486
}

Received: 10 July 2019; Accepted: 19 August 2019; Published: 22 August 2019

check for updates

\begin{abstract}
Zirconia $\left(\mathrm{ZrO}_{2}\right)$-based flame retardant coatings were synthesized through the process of grinding, mixing, and curing. The flame retardant coatings reinforced with zirconia nanoparticles $\left(\mathrm{ZrO}_{2} \mathrm{NPs}\right.$ ) were prepared at four different formulation levels marked by F0 (without adding $\mathrm{ZrO}_{2}$ NPs), F1 (1\% $\left.w / w \mathrm{ZrO}_{2} \mathrm{NPs}\right), \mathrm{F} 2$ (2\% $\left.w / w \mathrm{ZrO}_{2} \mathrm{NPs}\right)$, and F3 (3\% $w / w \mathrm{ZrO}_{2} \mathrm{NPs}$ ) in combination with epoxy resin, ammonium polyphosphate, boric acid, chitosan, and melamine. The prepared formulated coatings were characterized by flammability tests, combustion tests, and thermogravimetric analysis. Finally, char residues were examined with scanning electron microscopy (SEM) and energy-dispersive $X$-ray spectroscopy (EDS). The peak heat release rate (PHRR) of the controlled sample filled with functionalized $\mathrm{ZrO}_{2}$ NPs was observed to decrease dramatically with increasing functionalized $\mathrm{ZrO}_{2}$ NPs loadings. There was an increase in the limit of oxygen index (LOI) value with the increase in the weight percentage of $\mathrm{ZrO}_{2}$ NPs. The UL-94V data clearly revealed a V-1 rating for the F0 sample; however, with the addition of $\mathrm{ZrO}_{2} \mathrm{NPs}$, the samples showed enhanced properties with a V-0 rating. Thermal gravimetric analysis (TGA) results revealed that addition of $\mathrm{ZrO}_{2} \mathrm{NPs}$ Improved composite coating thermal stability at $800{ }^{\circ} \mathrm{C}$ by forming high residual char. The results obtained here reveal that the addition of $\mathrm{ZrO}_{2}$ NPs in the formulated coatings has shown the excellent impact as flame retardant coatings.
\end{abstract}

Keywords: $\mathrm{ZrO}_{2} \mathrm{NPs}$; intumescent flame retardant coatings; SEM; XRD; TGA

\section{Introduction}

$\mathrm{ZrO}_{2}$ material has good physical and chemical properties such as visually good color, high chemical stability, excellent anti-corrosive properties, high tensile strength, high hardness, and good mechanical and electrical properties [1,2]. Zirconia is used in a broad spectrum of applications, such as refractory products, ceramics, and electronic devices [3-7]. It is widely utilized in corrosive environments, and zirconium alloys can be used in pipes, steel alloys, and flame retardant coatings. Another anomalous property of zirconia-based materials is their high strength and low thermal conductivity, and some of the zirconium-oxide-containing ceramics can conduct oxygen ions [8-12]. Because of these properties, the zirconium-oxide-based materials are regarded as prominent materials compared to alumina ceramics $[13,14]$. Due to its high-temperature resistance, $\mathrm{ZrO}_{2}$ is used as filler in intumescent flame retardant coatings (IFRCs) [15-17].

The chemical entities or substances that have the ability to withstand direct flame and can increase the ignition resistance are called flame retardants. These are added to materials that do not have flame retardancy in order to improve their flame resistance properties [18]. Flame retardant materials are of two types: external and internal [19]. Flame can be inhibited by two methods: The first method is 
restricting the atmospheric oxygen from reaching the material by releasing non-combustible gases; and the second method depends on the thermal behavior of the flame retardant, which lead to reducing the heat at surface of the material and finally results in the extinguishing of the flame of the burning material [20]. Materials such as nitrogen, phosphorous, halogenated (organic), and non-halogenated (inorganic) substances or molecules can be used as flame retardant agents; these agents can increase the flame retardant properties of a material.

IFRC is considered as the most efficient and inexpensive way to safeguard products from fire and is usually applied on plastics, wood, and fabrics. It protects the materials against fire without changing the properties of the coated substances [21]. Intumescence is the phenomenon in which a substance swells upon heating and forms multi-cellular layers [22]. These layers act as thermal barriers that inhibit the flow of heat towards the material thereby protecting them against fire. The intumescent coating is usually composed of three parts: charring agent, acid source, and foaming agent. The quantities of these constituents must be optimized for the formation of an effective IFRC. Furthermore, inorganic fillers can also be added to these coating compositions for the improvement of flame retardant properties $[23,24]$. Very recently, it has been observed that the addition of inorganic fillers can sufficiently improve char morphology, thermal resistance, and fire retardation [25-27]. Nanofillers, on reaction with phosphate, can induce a synergistic effect in IFRCs. The well-known synergist candidates reported to date included $\mathrm{TiO}_{2}$ nanoparticles (NPs) [28] and $\mathrm{SiO}_{2} \mathrm{NPs}$ [29]. However, other types of nanofillers still need to be tested in order to identify their function in synergism for an intumescent scheme [30-32].

Previously, the zirconium and zirconium-containing fillers were incorporated in different flame retardant coatings in anticipation of obtaining enhanced properties [33-39]. An increase in the char residue, limit of oxygen index (LOI), and peak heat release rate (PHRR) values have been reported for coating samples containing zirconium silicate and zirconium phosphate. However, in the present work, the zirconia was added to the chitosan- and melamine-based epoxy coating. Compared to the previous works, zirconium oxide shows enhanced flame retardant properties in this system.

In this study, the impacts of $\mathrm{ZrO}_{2}$ inorganic nanofillers in the intumescent coating were explored as a fire-retardant composition coating. The $\mathrm{ZrO}_{2}$ was incorporated in IFRCs and the flammability and combustion properties were investigated using the UL-94V and microcalorimeter tests. The thermo-gravimetric assessment evaluated coating heat degradation behaviors. Finally, the morphology of the char residue obtained from the microcalorimetry was examined by SEM.

\section{Materials and Methods}

\subsection{Materials}

For this study, highly pure zirconium (IV) oxynitrate hydrate $\left(\mathrm{ZrO}\left(\mathrm{NO}_{3}\right)_{2} \cdot \mathrm{H}_{2} \mathrm{O}\right)$, sodium hydroxide $(\mathrm{NaOH})$, hydrofluoric acid (HF), flame retardant additive boric acid $\left(\mathrm{H}_{3} \mathrm{BO}_{3}\right)$, acid source ammonium polyphosphate $\left[\mathrm{NH}_{4} \mathrm{PO}_{3}\right]_{n}(\mathrm{OH})_{2}$, charring agent chitosan, and foaming agent melamine $\left(\mathrm{C}_{3} \mathrm{H}_{6} \mathrm{~N}_{6}\right)$ were acquired from Sigma Aldrich. Epoxy resin (Bisphenol) and amine hardener were procured from Sikadur-52 Company. Distilled water was purified by using the Baistra apparatus.

\subsection{Synthesis of $\mathrm{ZrO}_{2} \mathrm{NPs}$}

$\mathrm{ZrO}_{2} \mathrm{NP}$ synthesis was processed using the typical hydrothermal technique. A $0.1 \mathrm{M}$ $\mathrm{ZrO}\left(\mathrm{NO}_{3}\right)_{2} \cdot \mathrm{H}_{2} \mathrm{O}$ solution and a $0.2 \mathrm{M} \mathrm{NaOH}$ solution were prepared in distilled water. Fifty milliliters of each solution $\left(\mathrm{ZrO}\left(\mathrm{NO}_{3}\right) \cdot \mathrm{H}_{2} \mathrm{O}: \mathrm{NaOH} ; 1: 1\right)$ were mixed into the hydrothermal flask and kept in the oven at $150{ }^{\circ} \mathrm{C}$ for $3 \mathrm{~h}$. After $3 \mathrm{~h}$, precipitate formed in the mixed solution, and finally, the solution was centrifuged for $10 \mathrm{~min}$ at 10,000 rpm using a cooling centrifuge and washed with ethyl alcohol 10 times. The precipitate obtained was dried for two hours at $100{ }^{\circ} \mathrm{C}$, calcined at $700{ }^{\circ} \mathrm{C}$, and ground to acquire a fine powder of $\mathrm{ZrO}_{2}$ NPs. 


\subsection{Characterization}

The room temperature X-ray powder diffraction (XRD) profile of the synthesized $\mathrm{ZrO}_{2} \mathrm{NPs}$ was acquired. The sample's crystal structure and phase purity were explored, and the crystallite size was calculated from the XRD spectrum using the "Debye Scherrer" equation. The surface morphology of $\mathrm{ZrO}_{2}$ NPs was investigated by scanning electron microscopy (SEM; TESCAN, CZ/MIRA I LMH). The particle size was measured by Transmission electron microscopy (TEM) (FEI, TECNAI G2 TF20-ST). The transform infrared (FT-IR) spectrum was recorded on a JASCO, FT/IR-6300 FT-IR spectrometer in $\mathrm{KBr}$ pellets. Energy dispersive X-ray analysis (EDX) was used for the elemental composition of $\mathrm{ZrO}_{2}$ NPs.

\subsection{Preparation of Epoxy Flame Retardant Coatings Using $\mathrm{ZrO}_{2} \mathrm{NPS}$}

$\mathrm{ZrO}_{2}$ NPs were sonicated for $1 \mathrm{~h}$ until proper dispersion was achieved. The preparation of composite coatings involved three steps: grinding, mixing, and curing. Initially, APP, boric acid, melamine, chitosan, and $\mathrm{ZrO}_{2} \mathrm{NPs}$ were ground for $5 \mathrm{~min}$ to form a homogeneous combination and added to the composite epoxy resin and blended for $10 \mathrm{~min}$. The exact formulation ratio is shown in Table 1. After preparing the formulations, the samples were dried at room temperature for 4 days. The solid samples were then used for FTIR, flammability, combustion, and thermal characteristics.

Table 1. The ratio of formulation epoxy resin nanocomposites in $w / w \%$.

\begin{tabular}{ccccccc}
\hline Formulation & $\begin{array}{c}\text { Ammonium } \\
\text { Polyphosphate }\end{array}$ & Chitosan & Melamine & Boric Acid & ZrO $_{\mathbf{2}}$ NPs & $\begin{array}{c}\text { Bisphenol:Hardener } \\
\text { (2:1) }\end{array}$ \\
\hline F0 & 15 & 5 & 5 & 15 & 0 & 60 \\
F1 & 15 & 5 & 5 & 15 & 1 & 59 \\
F2 & 15 & 5 & 5 & 15 & 2 & 58 \\
F3 & 15 & 5 & 5 & 15 & 3 & 57 \\
\hline
\end{tabular}

\subsection{Characterization of Flame Retardant Coating Formulations Using FT-IR}

A Nicolet Aviator 360 FT-IR spectrometer instrument (Nicolet, USA) was used to record and monitor the sample infrared spectrum at a resolution of $2 \mathrm{~cm}^{-1}$. The sample infrared spectrum was recorded in the range of $4000-400 \mathrm{~cm}^{-1}$.

\subsection{Flammability, Combustion, and Thermal Characteristics of Flame Retardant Coatings}

The LOI test was performed using an HC-2C oxygen index instrument (China). Three coating layers were applied on $130 \mathrm{~mm} \times 6.5 \mathrm{~mm} \times 3.2 \mathrm{~mm}$ sized plywood sheets using the dip-coating method and analyzed according to the ASTM D2863 standard procedure. The Ul-94V test was conducted according to the ASTM D 3801 standard procedure. Before performing this study, dip-coated specimens were pre-treated at $23 \pm 1{ }^{\circ} \mathrm{C} / 50 \pm 5 \%$ relative humidity for 2 days, then $70{ }^{\circ} \mathrm{C}$ for 7 days using a hot air oven, and then cooled in a desiccator for a minimum of $4 \mathrm{~h}$. The sample specimens of dimensions $125 \mathrm{~mm}$ long, $13 \mathrm{~mm}$ wide and $3.1 \mathrm{~mm}$ thicknesses were reinforced in a vertical position and a flame was applied to the bottom of the sample specimen. The flame was obtained by adjusting the gas supply, and flame height was adjusted to $20 \mathrm{~mm}$. Finally, the rate of combustion of the composite coatings was determined by the vertical burning test followed by UL-94 V standards in an air atmosphere. The combustion behaviors, peak heat release rate (PHRR) and total heat release rate (TRR), were determined by a microcalorimeter instrument (Make Fire Testing Technology, United Kingdom, and Modal 11311). The test was conducted in accordance with the ISO 5660 guidelines. For this study, 4-5 mg of each sample was put into a thin-walled, quartz capillary crucible, kept in a sample holder, and heated at a constant rate of $260 \mathrm{~K} / \mathrm{min}$ with a temperature range of 90 to $800^{\circ} \mathrm{C}$. Thermogravimetric analysis was conducted on a thermogravimetric analyzer (Perkin-Elmer) instrument at a linear heating rate of $10^{\circ} \mathrm{C} \mathrm{min}-1$ in a nitrogen environment. The range of the temperature was kept at 30 to $800{ }^{\circ} \mathrm{C}$. The sample weight was taken at about $10 \mathrm{mg}$. 


\subsection{Morphology of Char Residues}

SEM, with a MIRA 3 LMU scanning electron microscope under $20 \mathrm{kV}$ voltage, was used to evaluate the morphological structures of the char residues, and elemental composition analysis of char residues was done by EDS after the calorimeter test.

\section{Results and Discussion}

\subsection{XRD Pattern of $\mathrm{ZrO}_{2} \mathrm{NPS}$}

The crystalline nature and phase purity of the resultant powder were assessed through room temperature XRD measurements (Figure 1). All the diffraction peaks of the $\mathrm{ZrO}_{2}$ sample were indexed according to the joint committee on powder diffraction standards (JCPDS) card number 80-0965. The $X R D$ pattern of the investigated sample confirmed the tetragonal phase (space group $=\mathrm{P} 42 / \mathrm{nmc}$ ). No additional peaks were found in the synthesized powder XRD pattern. The average crystallite size was calculated for the most intense diffraction peaks using Scherrer's formula:

$$
D=\frac{K \lambda}{\beta \operatorname{Cos} \theta}
$$

where $\beta$ (in radian) is a half maximum full width of XRD peaks, $K=0.94$ is the shape factor, $\lambda=$ $1.54178 \AA$ for $\mathrm{Cu}-\mathrm{K}_{\alpha} \mathrm{X}$-rays, and $\theta$ is the diffraction angle (in degree) corresponding to each plane. Crystallite size $(D)$ was found to be $80 \pm 5 \mathrm{~nm}$ for chemically synthesized $\mathrm{ZrO}_{2}$.

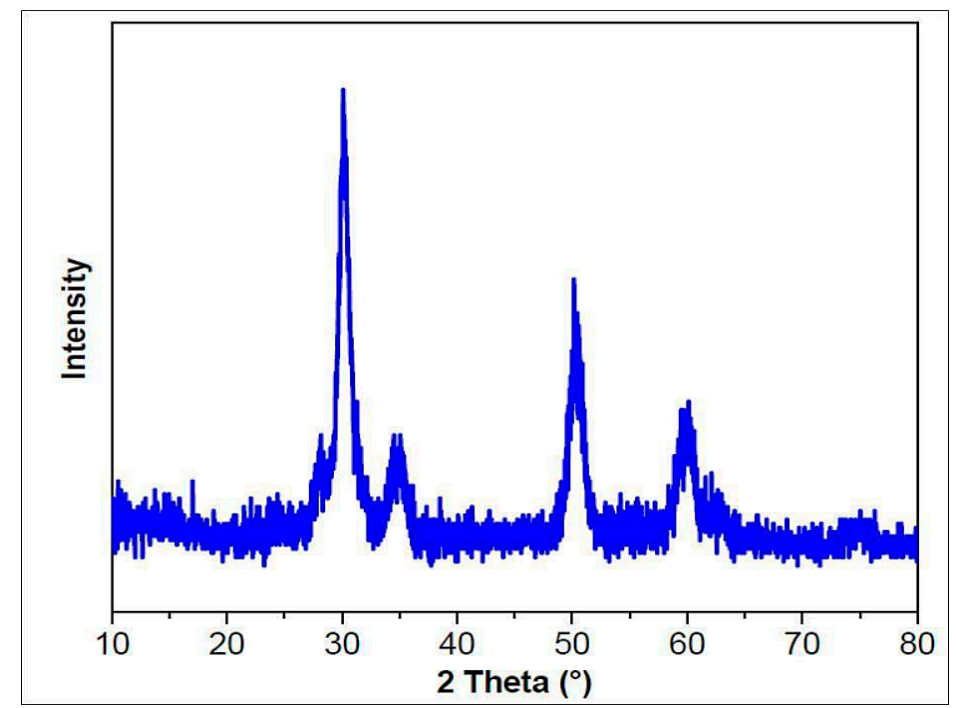

Figure 1. X-ray powder diffraction (XRD) pattern of $\mathrm{ZrO}_{2}$ nanoparticles (NPs).

\subsection{SEM Analysis of $\mathrm{ZrO}_{2} \mathrm{NPS}$}

The surface morphology of the acquired $\mathrm{ZrO}_{2}$ NPs was investigated using SEM and the obtained

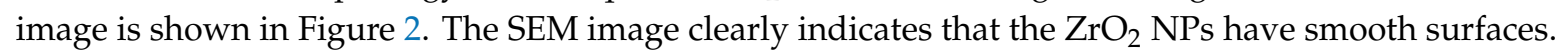
In the SEM images, the agglomeration of NPs was also visible.

\subsection{TEM Analysis of $\mathrm{ZrO}_{2} \mathrm{NPS}$}

Figure $3 \mathrm{a}$, b shows the TEM images and corresponding size distribution histogram of $\mathrm{ZrO}_{2} \mathrm{NPs}$. The figure indicates that $\mathrm{ZrO}_{2} \mathrm{NPs}$ were uniform and cylindrical in shape. The average particle size calculated was about $80 \mathrm{~nm}$ using Image-J software. 


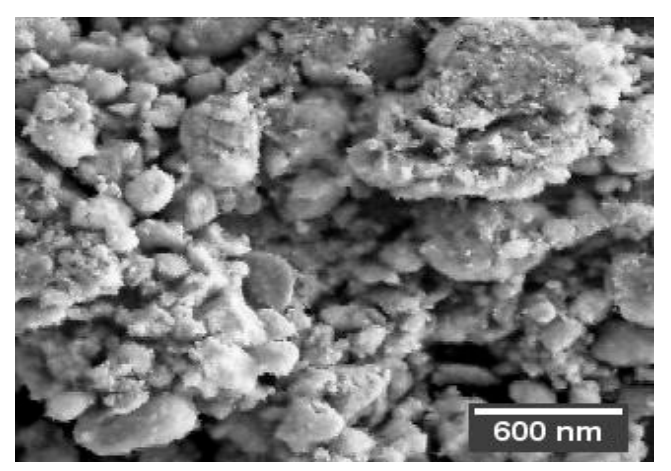

Figure 2. Scanning electron microscopy (SEM) image of $\mathrm{ZrO}_{2} \mathrm{NPs}$.

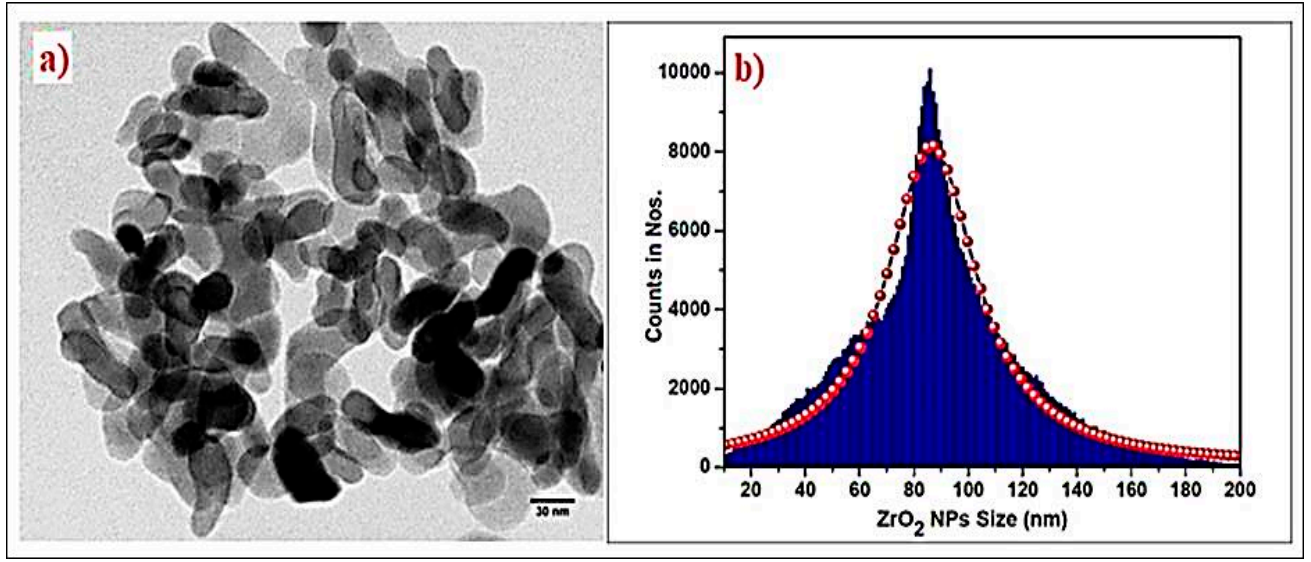

Figure 3. (a) Transmission electron microscopy (TEM) image and (b) distribution histogram of $\mathrm{ZrO}_{2}$ NPs.

\subsection{EDS Analysis of $\mathrm{ZrO}_{2} \mathrm{NPS}$}

The elemental composition of $\mathrm{ZrO}_{2}$ NPs was studied by EDS as shown in Figure 4. The $\mathrm{ZrO}_{2} \mathrm{NPs}$ exhibit three elemental peaks: two for the zirconium element located at 0.1 and $1.99 \mathrm{keV}$ and one for the oxygen element located at $0.57 \mathrm{keV}$. From EDS data, the weight ratio of $\mathrm{Zr}: \mathrm{O}$ was around 78:22. It is evident that the sample consisted of only ' $\mathrm{O}$ ' and ' $\mathrm{Zr}$ ' elements.

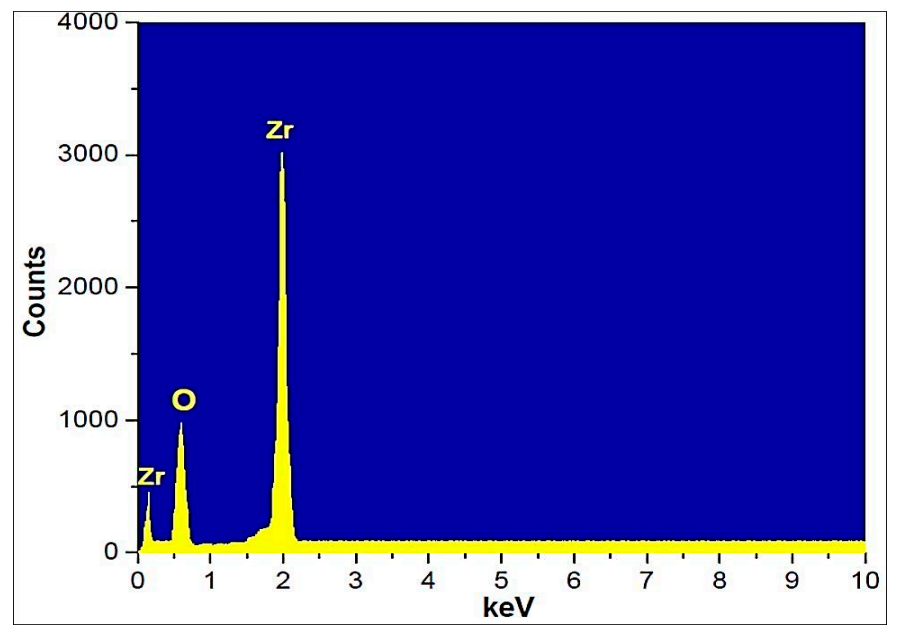

Figure 4. EDS of $\mathrm{ZrO}_{2}$ NPs. 


\subsection{FT-IR Analysis of $\mathrm{ZrO}_{2} \mathrm{NPs}$}

The FT-IR spectrum of $\mathrm{ZrO}_{2}$ NPs is shown in Figure 5. Due to the absorbed water molecules, the bands noted at $3424 \mathrm{~cm}^{-1}$ and $1637 \mathrm{~cm}^{-1}$ are attributed to the bending and stretching vibrations of the $\mathrm{O}-\mathrm{H}$ bond. The $1387 \mathrm{~cm}^{-1}$ band is ascribed to non-bridging $\mathrm{OH}$ groups being absorbed. The $735 \mathrm{~cm}^{-1}$ sharp band is characteristic of $\mathrm{m}-\mathrm{ZrO}_{2}$. The observed FT-IR peak at $503 \mathrm{~cm}^{-1}$ for the $\mathrm{ZrO}_{2}$ synthetic powders is ascribed to the $\mathrm{ZrO}_{3}{ }^{2-}$ group vibration modes, which confirms the formation of $\mathrm{ZrO}_{2}$.

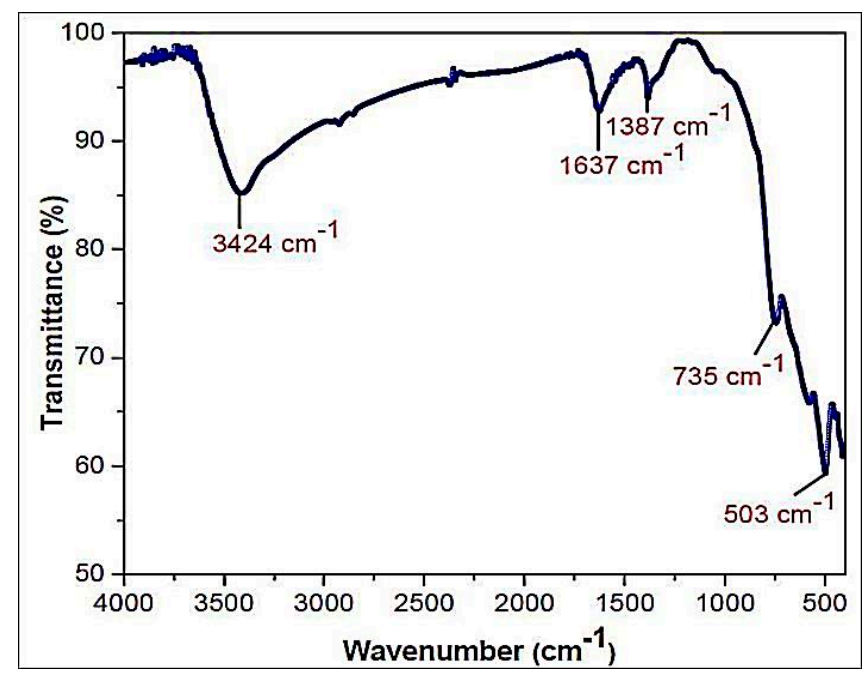

Figure 5. Transform infrared (FT-IR) spectra of $\mathrm{ZrO}_{2}$ NPs.

\subsection{Characterization of Flame-Retardant Coating Formulations Using FT-IR}

The FT-IR spectral technique was used to investigate the bonding interaction as well as identify functional groups in different formulations. The FT-IR spectra of Zr NPs, F0, and F3 samples are shown in Figure 6a-c. In these three spectra, a broad band appears at $3423 \mathrm{~cm}^{-1}$ because of the $\mathrm{OH}$ stretch of water molecules, and the bending vibrations around $1637 \mathrm{~cm}^{-1}$ are also due to the interlayer of $\mathrm{H}_{2} \mathrm{O}$. In Figure $6 \mathrm{a}, \mathrm{c}$, the observed FT-IR peak at $503 \mathrm{~cm}^{-1}$ for the $\mathrm{ZrO}_{2}$ synthetic powders is ascribed to the $\mathrm{ZrO}_{3}{ }^{2-}$ group vibration modes, which confirmed the formation of $\mathrm{ZrO}_{2}$. In Figure $6 \mathrm{~b}, \mathrm{c}$, the B-O-P bending vibrations are observed at $619 \mathrm{~cm}^{-1}$ [40], and the bands at 1157 and $1457 \mathrm{~cm}^{-1}$ are ascribed to the vibrations of the $\mathrm{P}-\mathrm{O}$ and $\mathrm{N}-\mathrm{H}$ groups, respectively. The peak at $3222 \mathrm{~cm}^{-1}$ is indicated as the $\mathrm{O}-\mathrm{H}$ group's fragile bending peaks and may be allocated to the absorption band of the phosphate group found at $1087 \mathrm{~cm}^{-1}$. In the region around $2227-2366 \mathrm{~cm}^{-1}$, the polyamide hardener caused a strong stretching vibration characteristic of $\mathrm{C}=\mathrm{N}$.

\subsection{Characterization of Flame-Retardant Coating Formulations Using XRD}

The XRD profiles of F0 and F3 formulations are shown in Figure 7. The sharp peaks of both formulations at $2 \theta \approx 14.4^{\circ}, 15.6^{\circ}$ (corresponding to APP) [41,42], 19.9 (showing chitosan) [43-45], $25.8^{\circ}$ (melamine) [46], and $28.0^{\circ}$ (boric acid) $[47,48]$ represent the crystalline patterns. Only the F3 formulation shows extra peaks of low intensity at $30.6^{\circ}, 40.4^{\circ}, 50.2^{\circ}$, and $59.1^{\circ}$, which are characteristics peaks corresponding to $\mathrm{ZrO}_{2}$ [8]. No peak shifting was observed with the addition of $\mathrm{ZrO}_{2}$, indicating that $3 \%(w / w) \mathrm{ZrO}_{2}$ additions do not affect the lattice parameters or the crystal structure of the host material. Furthermore, the almost similar intensity of the characteristic peaks in the XRD pattern of both the formulations points to the similar morphology of these materials. 


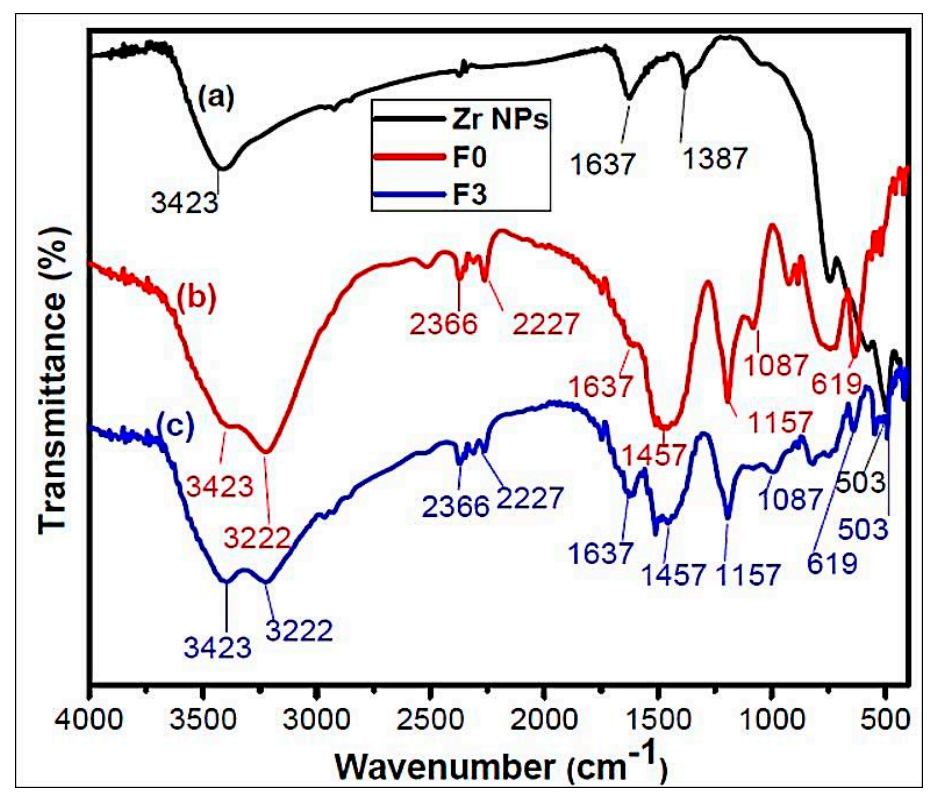

Figure 6. FT-IR spectra of (a) Pure Zr NPs, (b) F0, and (c) F3 samples.

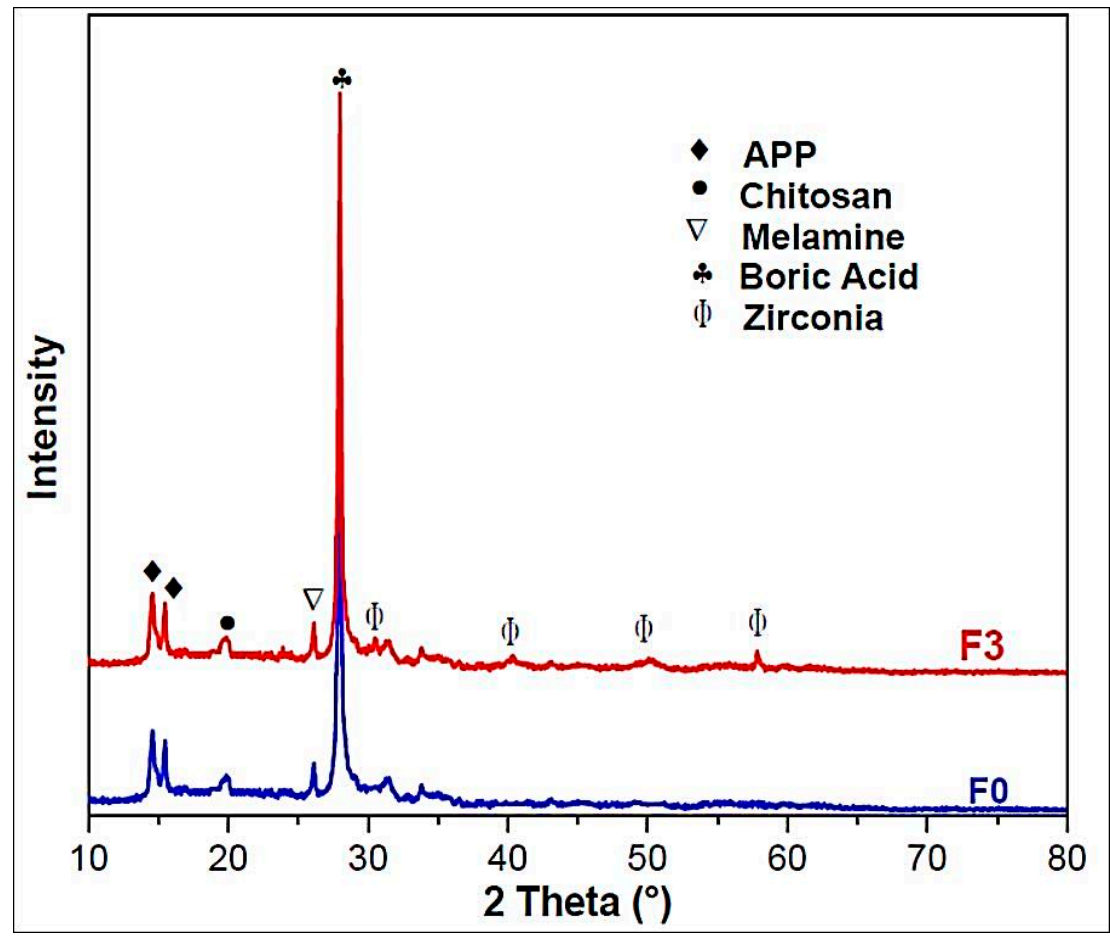

Figure 7. XRD pattern of F0 and F3 samples.

\subsection{Flammability Tests}

The Limit of Oxygen Index (LOI) and UL-94V

The LOI and UL $94 \mathrm{~V}$ tests were performed to evaluate the flame retardant properties of the formulated samples. The results of the LOI and UL 94 tests for the samples are presented in Table 2 and Figure 8. The LOI value of the F0 composite was $21.3 \%$; the pristine sample (F0) was highly flammable compared with $\mathrm{ZrO}_{2}$ NPs loaded samples (F1, F2, and F3). We observed that the LOI value increased when $\mathrm{ZrO}_{2} \mathrm{NPs}$ were added into the composition. When loading $1 \%(w / w) \mathrm{ZrO}_{2} \mathrm{NP}$, the LOI value of the $\mathrm{F} 1$ composite was $31.8 \%$. When increasing $\mathrm{ZrO}_{2} \mathrm{NPs}$ to $2 \%(w / w)$, the LOI value of the $\mathrm{F} 2$ composite was $35.4 \%$. At $3 \%(w / w) \mathrm{ZrO}_{2} \mathrm{NP}$ for loading sample $\mathrm{F} 3$, the $\mathrm{LOI}$ value was $38.7 \%$. 
Thus, $\mathrm{ZrO}_{2}$ NPs were more effective at improving the LOI values of formulations. According to the UL-94 V test, the F0 composite showed a V-1 rating. However, the content of $\mathrm{ZrO}_{2} \mathrm{NPs}$ at $1 \%, 2 \%$, and $3 \%$ of composites (F1, F2, and F3) could still pass the UL-94 V-0 rating. Based on these results, the flame-retardant efficiency of F1, F2, and F3 composites was much higher than that of the F0 composite. From the LOI and UL-94V results, we observed that the addition of $\mathrm{ZrO}_{2} \mathrm{NPs}$ can play a synergistic action up to an optimum loading concentration.

Table 2. Limit of oxygen index (LOI) and UL-94V ratings of composites.

\begin{tabular}{ccc}
\hline Code & LOI\% & Rating Results \\
\hline F0 & 21.3 & V-1 \\
F1 & 31.8 & V-0 \\
F2 & 35.4 & V-0 \\
F3 & 38.7 & V-0 \\
\hline
\end{tabular}

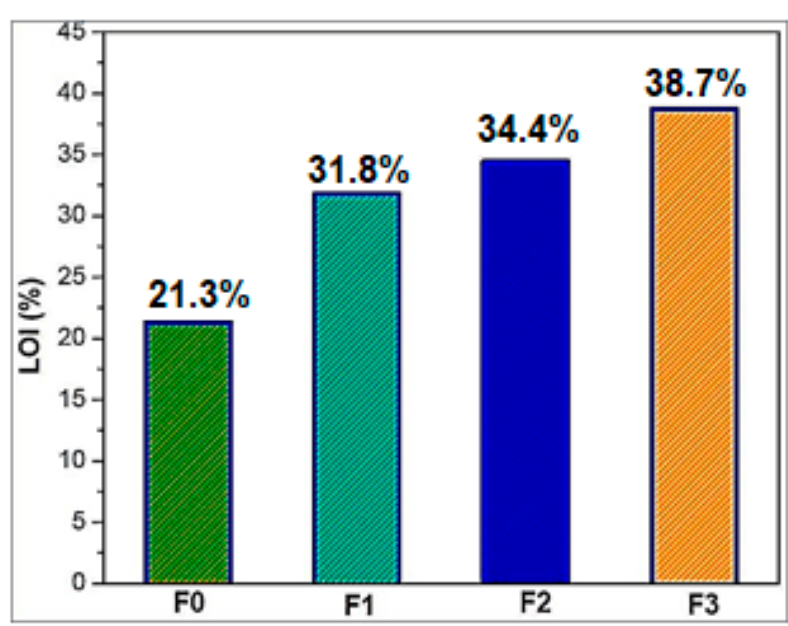

Figure 8. Effect of $\mathrm{ZrO}_{2} \mathrm{NPs}$ on the LOI test.

\subsection{Combustion Test}

The combustion properties of composites were studied by micro calorimetry. This study is used for ranking and comparing the fire behavior of a material. From this study, parameters such as PHRR, average heat release rate, total heat release (THR) and time to ignition (TTI) can be obtained. The PHRR values are indicated to evaluate fire safety. The results were obtained in the present work and presented in Table 3 and Figure 9.

Table 3. Microcalorimeter results of the epoxy/ZrO $\mathrm{ZPS}_{2}$.

\begin{tabular}{cccc}
\hline Formulation & TTI (sec) & PHRR (W/g) & THR (kJ/g) \\
\hline F0 & 188 & 76.3 & 22.1 \\
F1 & 276 & 28.7 & 7.0 \\
F2 & 278 & 23.5 & 5.5 \\
F3 & 281 & 18.9 & 3.7 \\
\hline
\end{tabular}

The combustion efficiency was increased in F1, F2, and F3 composites by adding $\mathrm{ZrO}_{2} \mathrm{NPs}_{\text {. The }}$ pristine sample (F0) burned very quickly after ignition and showed a PHRR peak in the range of $180-450 \mathrm{~s}$ with $76.3 \mathrm{~W} / \mathrm{g}$. With the addition of $1 \%, 2 \%$, and $3 \% \mathrm{ZrO}_{2} \mathrm{NPs}$ to the composite, the PHRR values of the F1, F2, and F3 samples showed $28.7 \mathrm{~W} / \mathrm{g}, 23.5 \mathrm{~W} / \mathrm{g}$ and $18.9 \mathrm{~W} / \mathrm{g}$, respectively. The F0, F1, F2, and F3 composites obtained only single peaks. The $\mathrm{ZrO}_{2} \mathrm{NPs}$ were involved in endothermal decomposition and released the moisture to form a dense, boron trioxide protective layer that protected the underlying material and improved the flame retardance. The TTI is a measurement from the onset 
of the PHRR curve of a sample. The TTI parameter is used to evaluate the flame retardant influence on the ignition of a material. Figure 10 and Table 3 clearly indicate that the F0 composite ignited at $188 \mathrm{~s}$ whereas the F1, F2, and F3 composites ignited at 276, 278, and $281 \mathrm{~s}$, respectively. During the combustion process, the intumescent flame retardant (IFR) system decomposes gently and results in char formation. In addition to this, the loading of $\mathrm{ZrO}_{2}$ NPs into the coating system the intumescent mechanism occurs gently. This might be the reason for the decrease in TTI values. The formation of char does not allow oxygen flow and heat transfer, hence the PHRR and THR values decrease. Among all composites, the F3 composite coating showed lower PHRR and THR values, which may be due to $\mathrm{ZrO}_{2}$ NPs hastening the esterification reaction in the IFR system during the combustion process to form a protective char.

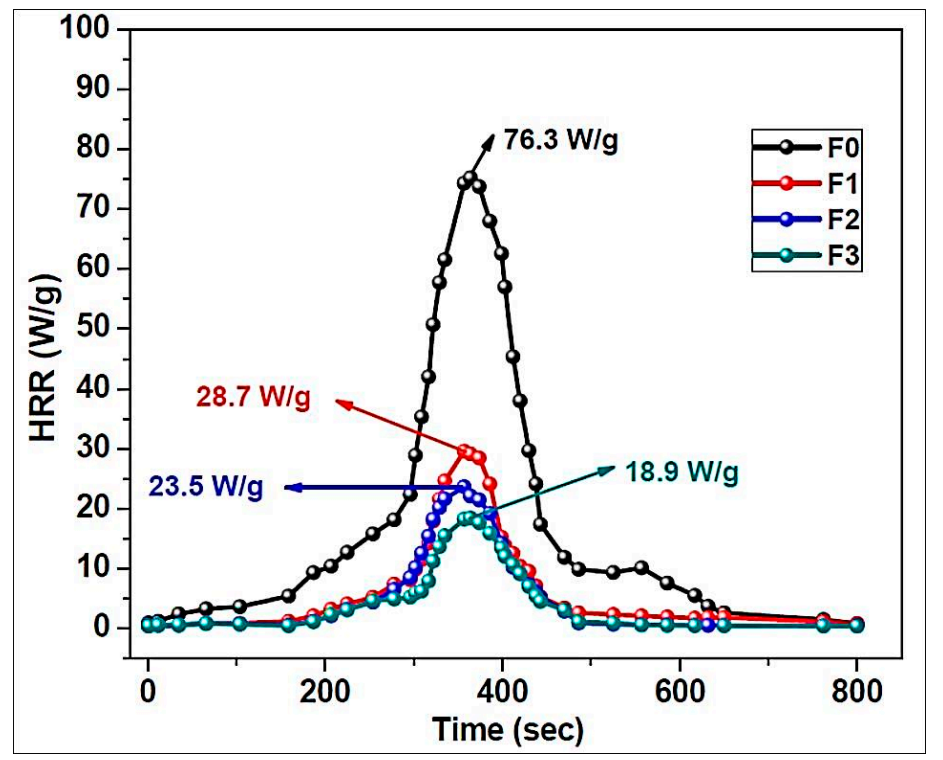

Figure 9. Peak heat release rate curves of the flame retardant samples.

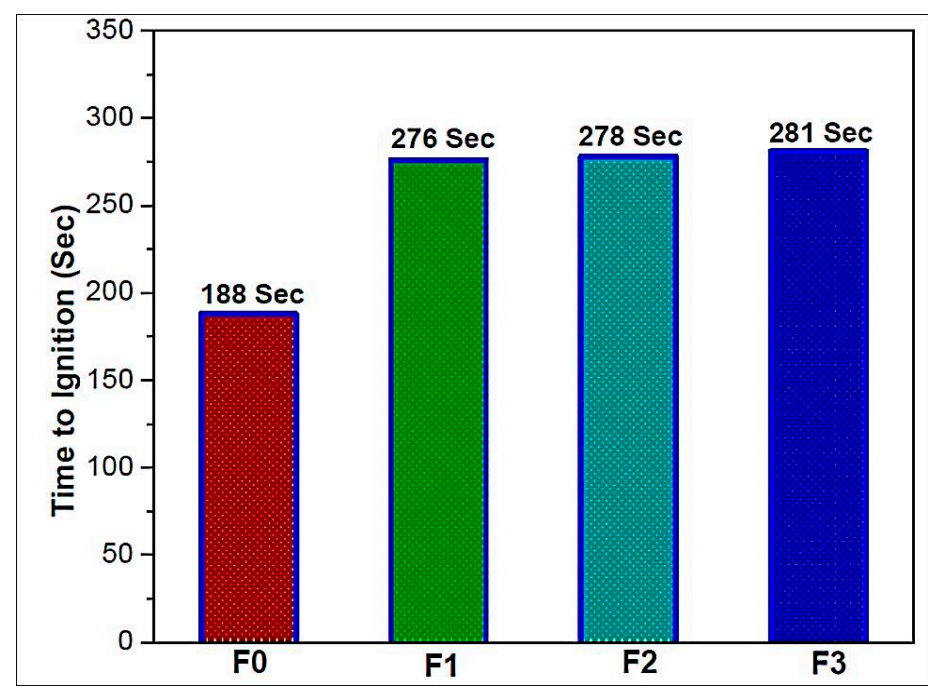

Figure 10. Time to ignition values of the flame retardant samples.

\subsection{Thermal Stability Test}

The thermal stability and decomposition pattern of individual components (APP, chitosan, melamine, boric acid, epoxy resin, hardener mixture, and zirconia) and formulations (F0, F1, F2, and F3) were established through TGA under nitrogen gas atmosphere. TGA analysis was performed in the inert gas atmosphere for the determination of the thermal degradation of the sample, because using an 
air or oxygen atmosphere may cause the sample to undergo thermal oxidation. Figures 11 and 12 and Table 4 represent the TGA and differential thermogravimetric (DTG) results of individual components and F0, F1, F2, and F3 formulations. From these data, the F0 showed thermal decomposition starting at $\approx 241.2{ }^{\circ} \mathrm{C}$ and $18.1 \%$ char residue at $800{ }^{\circ} \mathrm{C}$. After $250{ }^{\circ} \mathrm{C}$, the IFR system F0 sample was involved in the intumescent mechanism. At this temperature, chitosan ammonium polyphosphate and melamine borate starts to decompose and release mineral acids such as phosphoric acid and meta-phosphoric acid, a polyhydric alcohol and polyhydric phosphates, boron trioxide, and melon, which removes the water content and $\mathrm{NH}_{3}$ gas from the IFR system by an esterification process; this finally leads to the formation of a protective phosphor-carbonaceous char layer that prevents the oxygen flow and heat transfer. APP and chitosan can easily participate in the phosphor-esterification reaction because chitosan has an abundant, amount of $\mathrm{OH}$ groups.

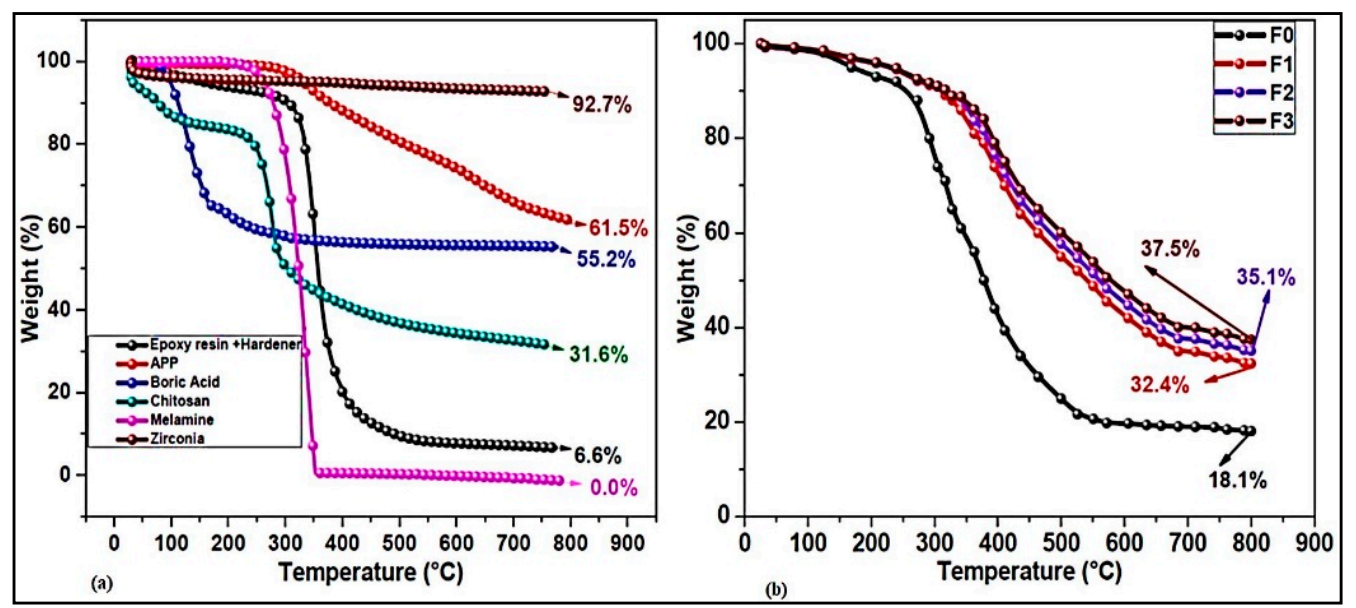

Figure 11. Thermal gravimetric analysis (TGA) graph of the (a) individual components and (b) flame retardant samples.

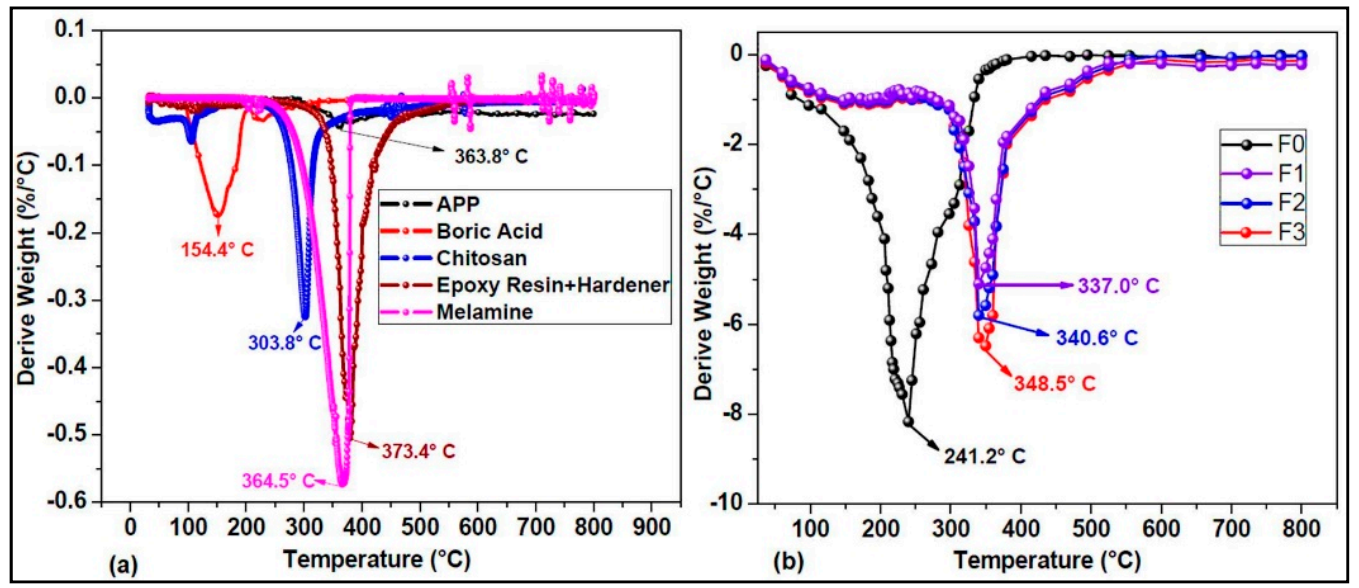

Figure 12. Differential thermogravimetric (DTG) graph of the (a) individual components and (b) flame retardant samples. 
Table 4. Thermal stability results of the flame retardant components and formulation samples.

\begin{tabular}{ccc}
\hline Code & Decomposition Temp. $\approx\left({ }^{\circ} \mathbf{C}\right)$ & Char Residue $(\mathbf{\%})$ at $\mathbf{8 0 0}{ }^{\circ} \mathbf{C}$ \\
\hline APP & 363.8 & 61.5 \\
Boric Acid & 154.4 & 55.2 \\
Chitosan & 303.8 & 31.6 \\
Epoxy Resin and Hardener & 373.4 & 6.6 \\
Mixture & 364.5 & 0.0 \\
Melamine & - & 92.7 \\
$*$ Zirconia & 241.2 & 18.1 \\
F0 & 337.0 & 32.4 \\
F1 & 340.6 & 35.1 \\
F2 & 348.5 & 37.5 \\
F3
\end{tabular}

* Experiment was conducted from ambient temperature to $800^{\circ} \mathrm{C}$. In between, the component did not decompose.

The differential thermal analysis (DTA) curve (Figure 12a) clearly shows that the thermal decomposition of APP, boric acid, chitosan, epoxy resin + hardener, and melamine started at 363.8, $154.4,303.8,373.4$ and $364.5^{\circ} \mathrm{C}$, respectively. The decomposition temperature was changed by adding Zr NPs to formulations (F1, F2, and F3). For formulation samples F1, F2, and F3, thermal decomposition started at $337.0,340.6$, and $348.5^{\circ} \mathrm{C}$ (Figure 12b), respectively. At these temperatures, weight loss began for F1, F2, and F3 formulations samples could be due to the release of $\mathrm{H}_{2} \mathrm{O}$ and $\mathrm{CO}_{2}$ from epoxy resin; the formation of phosphoric acid, polyphosphoric acid, and met phosphoric acid with decomposition of APP [49,50]; the formation of polyhydrated alcohols from chitosan [51]; the formation of $\mathrm{NH}_{3}$ gas from melamine and decomposed boric acid; or the release of boron trioxide. The char residues obtained at $800{ }^{\circ} \mathrm{C}$ of F1, F2, and F3 samples were $32.4 \%, 35.1 \%$ and $37.5 \%$, respectively. Among the investigated composites, the F3 sample showed higher char $\%$ at $800{ }^{\circ} \mathrm{C}$. This may be because the char layer formed and inhibited the emission of the pyrolysis gases due to the enhanced heat-shielding effect, and because Zr NPs have a superior surface-to-volume ratio but are incredibly difficult to distribute evenly. Thus, the Zr NP mass percentage performs a significant role in improving the intumescent flame retardant coating.

\subsection{Char Morphology Analysis Flame Retardant Coatings}

\subsubsection{SEM Analysis}

The micro-morphologies of the char layers after calorimeter test for F0, F1, F2 and F3 composites were investigated by SEM. Figure 13a-d shows the morphology on the surface of F0, F1, F2, and F3 samples at a $3000 \times$ magnification level. Figure 12a shows that the surface of the char layer for the F0 sample (the sample without $\mathrm{ZrO}_{2} \mathrm{NPs}$ ) contains large holes. The char layer with large holes of micron size did not provide protection against fire. The char morphology of F1, F2, and F3 formulations in Figure $12 \mathrm{~b}-\mathrm{d}$ indicates that large holes and cracks gradually reduced the addition of $\mathrm{ZrO}_{2} \mathrm{NPs}(1 \%$, $2 \%$, and $3 \%$ ). The holes and cracks that are formed in the F0 char may be due to the release and flow of volatile gases into the flame zone. 

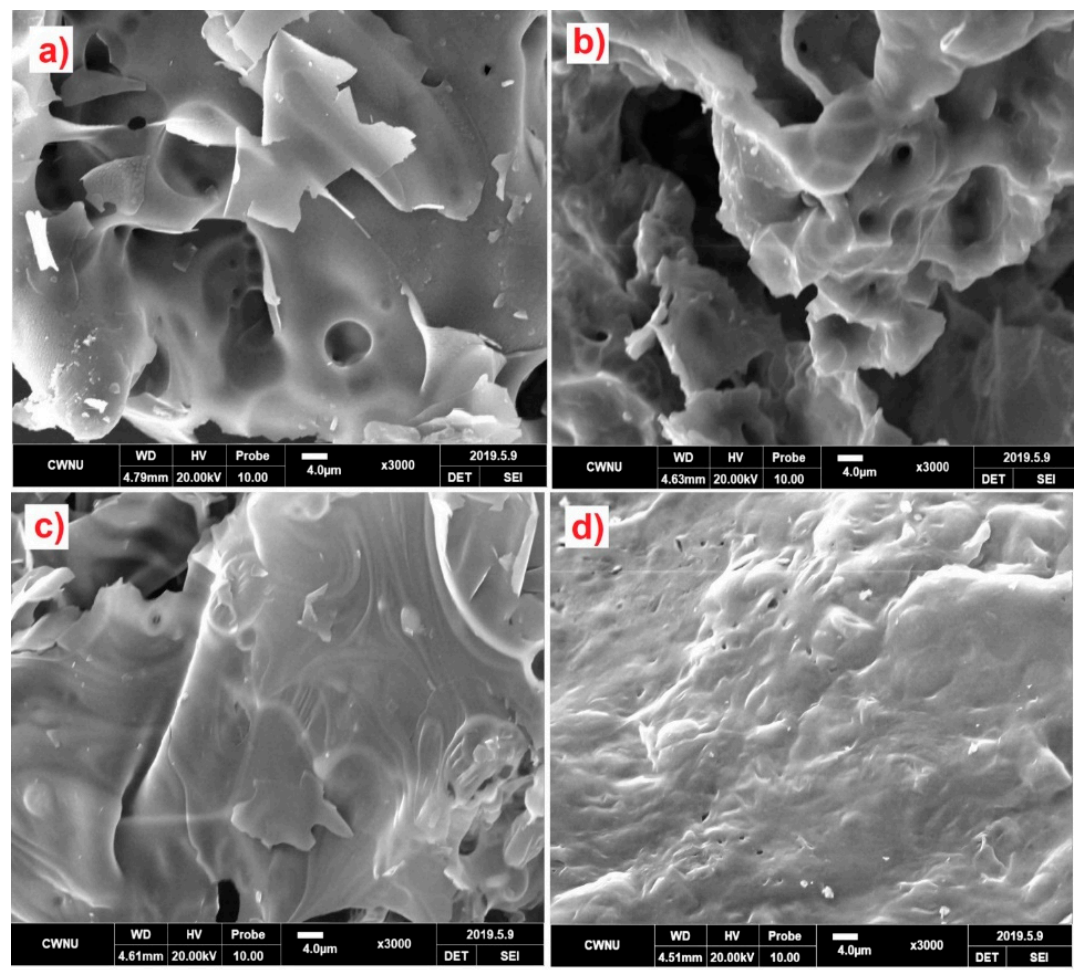

Figure 13. SEM images of the flame retardant char samples (a) F0, (b) F1, (c) F2, and (d) F3.

\subsubsection{EDS Analysis}

The EDS spectra of the F0 and F3 formulations are shown in Figure 14. There are five significant peaks - boron, carbon, nitrogen, oxygen, and phosphorus-according to the EDS spectra in Figure 14a. These results were compatible with the composition of the F0 formulation used for ammonium polyphosphate, boric acid, chitosan, and melamine. There are six significant peaks-boron, carbon, nitrogen, oxygen, zirconia, and phosphorus-in Figure 14b. These results were compatible with the composition of the F3 formulation used for zirconia NPs, ammonium polyphosphate, boric acid, chitosan, and melamine. These results are in good agreement with previously reported results [52].

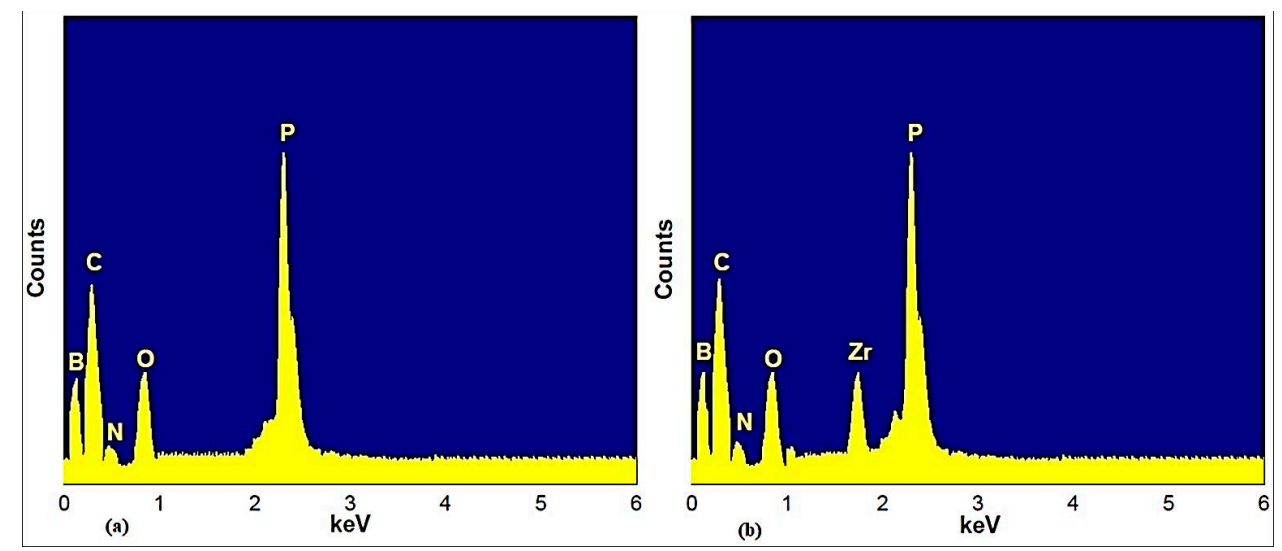

Figure 14. EDS spectra of the flame retardant char samples (a) F0 and (b) F3.

\section{Conclusions}

In this study, LOI and UL94 test results showed that the influence of $\mathrm{ZrO}_{2} \mathrm{NPs}$ in flame-retardant coatings increased the LOI value to $38.71 \%$ with the loading of $6.0 \mathrm{wt} \% \mathrm{ZrO}_{2} \mathrm{NPs}$. The composite formulations F1, F2, and F3 could exceed UL $94 \mathrm{~V}-0$ with the loading of $1-3 \mathrm{wt} \% \mathrm{ZrO}_{2} \mathrm{NPs}$. From micro calorimeter data, increasing the percentage of $\mathrm{ZrO}_{2} \mathrm{NPs}$ in flame-retardant coatings decreased 
the PHRR values as well as the THR results. The TGA data clearly indicates that the addition of $\mathrm{ZrO}_{2}$ NPs can greatly increases the thermal stability of the coating by increasing the char residue percentage at $800^{\circ} \mathrm{C}$. Based on the char morphology results, we conclude that the addition of $\mathrm{ZrO}_{2} \mathrm{NPs}$ at an optimum level can strengthen the char and increase the flame retardancy of coatings. Overall, the addition of $\mathrm{ZrO}_{2}$ NPs to IFRCs has shown improved results in terms of protecting the substrate materials against fire.

Author Contributions: B.H.K. conceived and designed the experiments and supervised the research work; T.N.R. performed the experiments and wrote the paper; I.H. measured the characterizations; J.E.L. and A.K. contributed reagents/materials/analysis tools.

Funding: This research was funded by the Korea National Research Foundation grant financed by the Korean government (No. 2018R1A6A1A03024509).

Conflicts of Interest: The authors declare no conflict of interest.

\section{References}

1. Giúdice, C.; Benítez, J. Zinc borates as flame-retardant pigments in chlorine-containing coatings. Prog. Org. Coat. 2001, 42, 82-88. [CrossRef]

2. Minegishi, S.; Tsuchida, S.; Sasaki, M.; Kameyama, A.; Kudo, H.; Nishikubo, T. Synthesis of polyphosphonates containing pendant chloromethyl groups by the polyaddition of bis (oxetane) $\mathrm{s}$ with phosphonic dichlorides. J. Polym. Sci. Part A Polym. Chem. 2002, 40, 3835-3846. [CrossRef]

3. Toldy, A.; Szolnoki, B.; Marosi, G. Flame retardancy of fibre-reinforced epoxy resin composites for aerospace applications. Polym. Degrad. Stab. 2011, 96, 371-376. [CrossRef]

4. Ahmad, T.; Ahmad, M.S.T. Hydrothermal Synthesis, Characterization and Dielectric Properties of Zirconia Nanoparticles. Mater. Sci. Eng. Int. J. 2017. [CrossRef]

5. Ajith, A.; Xian, G.; Li, H.; Sheriff, Z.; Thomas, S. Surface grafting of flax fibers with hydrous zirconia nanoparticles and the effects on the tensile and bonding properties. J. Compos. Mater. 2016, 50, 627-635. [CrossRef]

6. Arreche, R.; Bellotti, N.; Blanco, M.; Vázquez, P. Synthesis and Characterization of Zirconium Oxides for Use as Antimicrobial Additives in Paints. Procedia Mater. Sci. 2015, 9, 627-634. [CrossRef]

7. Behbahani, A.; Rowshanzamir, S.; Esmaeilifar, A. Hydrothermal Synthesis of Zirconia Nanoparticles from Commercial Zirconia. Procedia Eng. 2012, 42, 908-917. [CrossRef]

8. Basahel, S.N.; Ali, T.T.; Mokhtar, M.; Narasimharao, K. Influence of crystal structure of nanosized $\mathrm{ZrO}_{2}$ on photocatalytic degradation of methyl orange. Nanoscale Res. Lett. 2015, 10, 113. [CrossRef]

9. Ehrlich, H.; Simon, P.; Motylenko, M.; Wysokowski, M.; Bazhenov, V.V.; Galli, R.; Stelling, A.L.; Stawski, D.; Ilan, M.; Stöcker, H.; et al. Extreme Biomimetics: Formation of zirconium dioxide nanophase using chitinous scaffolds under hydrothermal conditions. J. Mater. Chem. B 2013, 1, 5092-5099. [CrossRef]

10. Bumajdad, A.; Nazeer, A.A.; Al Sagheer, F.; Nahar, S.; Zaki, M.I. Controlled Synthesis of $\mathrm{ZrO}_{2}$ Nanoparticles with Tailored Size, Morphology and Crystal Phases via Organic/Inorganic Hybrid Films. Sci. Rep. 2018, 8, 3695. [CrossRef]

11. Eshed, M.; Pol, S.; Gedanken, A.; Balasubramanian, M. Zirconium nanoparticles prepared by the reduction of zirconium oxide using the RAPET method. Beilstein J. Nanotechnol. 2011, 2, 198-203. [CrossRef]

12. Fathima, J.B.; Pugazhendhi, A.; Venis, R. Synthesis and characterization of $\mathrm{ZrO}_{2}$ nanoparticles-antimicrobial activity and their prospective role in dental care. Microb. Pathog. 2017, 110, 245-251. [CrossRef]

13. Jayakumar, S.; Ananthapadmanabhan, P.; Perumal, K.; Thiyagarajan, T.; Mishra, S.; Su, L.; Tok, A.; Guo, J. Characterization of nano-crystalline $\mathrm{ZrO}_{2}$ synthesized via reactive plasma processing. Mater. Sci. Eng. B 2011, 176, 894-899. [CrossRef]

14. Maridurai, T.; Balaji, D.; Sagadevan, S. Synthesis and Characterization of Yttrium Stabilized Zirconia Nanoparticles. Mater. Res. 2016, 19, 812-816. [CrossRef]

15. Precious-Ayanwale, A.; Donohue-Corenjo, A.; Cuevas-Gonzalex, J.C.; Espinosa-Cristobal, L.F.; Reyes-Lopez, S.Y. Review of The Synthesis, Characterization, and Application of Zirconia Mixed Metal Oxide Nanoparticles. Int. J. Res. 2018, 6, 136-145. 
16. Tyagi, B.; Sidhpuria, K.; Shaik, B.; Jasra, R.V. Synthesis of Nanocrystalline Zirconia Using Sol-Gel and Precipitation Techniques. Ind. Eng. Chem. Res. 2006, 45, 8643-8650. [CrossRef]

17. Siddiqui, M.R.H.; Al-Wassil, A.I.; Al-Otaibi, A.M.; Mahfouz, R.M. Effects of precursor on the morphology and size of $\mathrm{ZrO}_{2}$ nanoparticles. synthesized by sol-gel method in a non-aqueous medium. Mater. Res. 2012, 15, 986-989. [CrossRef]

18. Rauta, P.; Manivasakan, P.; Rajendran, V.; Sahu, B.; Panda, B.; Mohapatra, P. Phase transformation of $\mathrm{ZrO}_{2}$ nanoparticles produced from zircon. Phase Transit. 2012, 85, 13-26. [CrossRef]

19. Negahdary, M.; Habibi-Tamijani, A.; Asadi, A.; Ayati, S. Synthesis of Zirconia Nanoparticles and Their Ameliorative Roles as Additives Concrete Structures. J. Chem. 2013, 2013, 314862. [CrossRef]

20. Dzyazko, Y.S.; Volfkovich, Y.M.; Sosenkin, V.E.; Nikolskaya, N.F.; Gomza, Y.P. Composite inorganic membranes containing nanoparticles of hydrated zirconium dioxide for electrodialytic separation. Nanoscale Res. Lett. 2014, 9, 271. [CrossRef]

21. Battegazzore, D.; Alongi, J.; Fontaine, G.; Frache, A.; Bourbigot, S.; Malucelli, G. Bulk vs. surface flame retardancy of fully bio-based polyamide 10, 10. RSC Adv. 2015, 5, 39424-39432. [CrossRef]

22. Liu, X.; Guo, J.; Sun, J.; Gu, X.; Feng, W.; Liu, W.; Li, H.; Zhang, S. The preparation of a bisphenol A epoxy resin based ammonium polyphosphate ester and its effect on the char formation of a fire-resistant transparent coating. Prog. Org. Coat. 2019, 129, 349-356. [CrossRef]

23. Shi, Y.; Wang, G. The novel epoxy/PEPA phosphate flame retardants: Synthesis, characterization and application in transparent intumescent fire resistant coatings. Prog. Org. Coat. 2016, 97, 1-9. [CrossRef]

24. Shi, Y.; Wang, G. The novel silicon-containing epoxy/PEPA phosphate flame retardant for transparent intumescent fire resistant coating. Appl. Surf. Sci. 2016, 385, 453-463. [CrossRef]

25. Da Silveira, M.R.; Peres, R.S.; Moritz, V.F.; Ferreira, C.A. Intumescent Coatings Based on Tannins for Fire Protection. Mater. Res. 2019, 22. [CrossRef]

26. Ullah, S.; Ahmad, F. Effects of zirconium silicate reinforcement on expandable graphite based intumescent fire retardant coating. Polym. Degrad. Stab. 2014, 103, 49-62. [CrossRef]

27. Xing, W.; Zhang, P.; Song, L.; Wang, X.; Hu, Y. Effects of alpha-zirconium phosphate on thermal degradation and flame retardancy of transparent intumescent fire protective coating. Mater. Res. Bull. 2014, 49, 1-6. [CrossRef]

28. Aziz, H.; Ahmad, F.; Zia-ul-Mustafa, M. Effect of Titanium Oxide on Fire Performance of Intumescent Fire Retardant Coating. Adv. Mater. Res. 2104, 935, 224-228. [CrossRef]

29. Wang, Z.; Han, E.; Liu, F.; Ke, W. Fire and Corrosion Resistances of Intumescent Nano-coating Containing Nano-SiO 2 in Salt Spray Condition. J. Mater. Sci. Technol. 2010, 26, 75-81. [CrossRef]

30. Xu, B.; Wu, X.; Ma, W.; Qian, L.; Xin, F.; Qiu, Y. Synthesis and characterization of a novel organic-inorganic hybrid char-forming agent and its flame-retardant application in polypropylene composites. J. Anal. Appl. Pyrolysis 2018, 134, 231-242. [CrossRef]

31. Yan, L.; Xu, Z.; Wang, X. Synergistic effects of organically modified montmorillonite on the flame-retardant and smoke suppression properties of transparent intumescent fire-retardant coatings. Prog. Org. Coat. 2018, 122, 107-118. [CrossRef]

32. Yang, Z.; Peng, H.; Wang, W.; Liu, T. Crystallization behavior of poly ( $\varepsilon$-caprolactone)/layered double hydroxide nanocomposites. J. Appl. Polym. Sci. 2010, 116, 2658-2667. [CrossRef]

33. Gillani, Q.F.; Ahmad, F.; Mutalib, M.I.A.; Megat-Yusoff, P.S.M.; Ullah, S. Effects of Halloysite Nanotube Reinforcement in Expandable Graphite Based Intumescent Fire Retardant Coatings Developed Using Hybrid Epoxy Binder System. Chin. J. Polym. Sci. Engl. Ed. 2018, 36, 1286-1296. [CrossRef]

34. Liu, X.Q.; Wang, D.Y.; Wang, X.L.; Chen, L.; Wang, Y.Z. Synthesis of functionalized $\alpha$-zirconium phosphate modified with intumescent flame retardant and its application in poly (lactic acid). Polym. Degrad. Stab. 2013, 98, 1731-1737. [CrossRef]

35. Lu, H.; Wilkie, C.A.; Ding, M.; Song, L. Thermal properties and flammability performance of poly (vinyl alcohol)/ $\alpha$-zirconium phosphate nanocomposites. Polym. Degrad. Stab. 2011, 96, 885-891. [CrossRef]

36. Alongi, J.; Frache, A. Flame retardancy properties of $\alpha$-zirconium phosphate based composites. Polym. Degrad. Stab. 2010, 95, 1928-1933. [CrossRef]

37. Yang, D.; Hu, Y.; Song, L.; Nie, S.; He, S.; Cai, Y. Catalyzing carbonization function of $\alpha$-ZrP based intumescent fire retardant polypropylene nanocomposites. Polym. Degrad. Stab. 2008, 93, 2014-2018. [CrossRef] 
38. Li, K.; Lei, H.; Zeng, X.; Li, H.; Lai, X.; Chai, S. Preparation of a flame retardant phosphorus-containing polyacrylate/ $\alpha$-zirconium phosphate nanocomposite through: In situ emulsion polymerization. RSC Adv. 2017, 7, 49290-49298. [CrossRef]

39. Liu, Q.; Song, L.; Lu, H.; Hu, Y.; Wang, Z.; Zhou, S. Study on combustion property and synergistic effect of intumescent flame retardant styrene butadiene rubber with metallic oxides. Polym. Adv. Technol. 2009, 20, 1091-1095. [CrossRef]

40. Ullah, S.; Ahmad, F.; Shariff, A.M.; Bustam, M.A.; Gonfa, G.; Gillani, Q.F. Effects of ammonium polyphosphate and boric acid on the thermal degradation of an intumescent fire retardant coating. Prog. Org. Coat. 2017, 109, 70-82. [CrossRef]

41. Zheng, Z.; Liu, Y.; Zhang, L.; Dai, B.; Yang, X.; Wang, H. Fabrication of halogen-free ammonium phosphate with two components via a simple method and its flame retardancy in polypropylene composites. J. Therm. Anal. Calorim. 2017, 127, 2013-2023. [CrossRef]

42. Shao, Z.B.; Deng, C.; Tan, Y.; Yu, L.; Chen, M.J.; Chen, L.; Wang, Y.Z. Ammonium polyphosphate chemically-modified with ethanolamine as an efficient intumescent flame retardant for polypropylene. J. Mater. Chem. A 2014, 2, 13955-13965. [CrossRef]

43. Abdeen, Z.; Mohammad, S.G.; Mahmoud, M. Adsorption of Mn (II) ion on polyvinyl alcohol/chitosan dry blending from aqueous solution. Environ. Nanotechnol. Monit. Manag. 2015, 3, 1-9. [CrossRef]

44. Mohanasrinivasan, V.; Mishra, M.; Paliwal, J.S.; Singh, S.K.; Selvarajan, E.; Suganthi, V.; Subathra Devi, C. Studies on heavy metal removal efficiency and antibacterial activity of chitosan prepared from shrimp shell waste. 3 Biotech 2014, 4, 167-175. [CrossRef] [PubMed]

45. Kumar, S.; Koh, J. Physiochemical, Optical and Biological Activity of Chitosan-Chromone Derivative for Biomedical Applications. Int. J. Mol. Sci. 2012, 13, 6102-6116. [CrossRef]

46. Sangeetha, V.; Kanagathara, N.; Sumathi, R.; Sivakumar, N.; Anbalagan, G. Spectral and Thermal Degradation of Melamine Cyanurate. J. Mater. 2013, 2013, 262094. [CrossRef]

47. Coşkuner, B.; Figen, A.K.; Piskin, M.B. The use of boric acid $\left(\mathrm{H}_{3} \mathrm{BO}_{3}\right)$ and boron oxide $\left(\mathrm{B}_{2} \mathrm{O}_{3}\right)$ for co-precipitation synthesis of cobalt-boron catalysts: Catalytic activity in hydrogen generation. Kinet. Catal. 2014, 55, 809-823. [CrossRef]

48. Gillani, Q.F.; Ahmad, F.; Mutalib, M.A.; Megat-Yusoff, P.S.; Ullah, S.; Messet, P.J.; Zia-Ul-Mustafa, M. Thermal degradation and pyrolysis analysis of zinc borate reinforced intumescent fire retardant coatings. Prog. Org. Coat. 2018, 123, 82-98. [CrossRef]

49. Jimenez, M.; Guin, T.; Bellayer, S.; Dupretz, R.; Bourbigot, S.; Grunlan, J.C. Microintumescent mechanism of flame-retardant water-based chitosan-ammonium polyphosphate multilayer nanocoating on cotton fabric. $J$. Appl. Polym. Sci. 2016, 133. [CrossRef]

50. Fang, F.; Zhang, X.; Meng, Y.; Gu, Z.; Bao, C.; Ding, X.; Li, S.; Chen, X.; Tian, X. Intumescent flame retardant coatings on cotton fabric of chitosan and ammonium polyphosphate via layer-by-layer assembly. Surf. Coat. Technol. 2015, 262, 9-14. [CrossRef]

51. Carosio, F.; Alongi, J. Flame Retardant Multilayered Coatings on Acrylic Fabrics Prepared by One-Step Deposition of Chitosan/Montmorillonite Complexes. Fibers 2018, 6, 36. [CrossRef]

52. Gao, Y.; Wang, Q.; Lin, W. Ammonium Polyphosphate Intercalated Layered Double Hydroxide and Zinc Borate as Highly Efficient Flame Retardant Nanofillers for Polypropylene. Polymers 2018, 10, 1114. [CrossRef] [PubMed]

(C) 2019 by the authors. Licensee MDPI, Basel, Switzerland. This article is an open access article distributed under the terms and conditions of the Creative Commons Attribution (CC BY) license (http://creativecommons.org/licenses/by/4.0/). 